\title{
O Contexto das emancipações na década de 1980: $O$ caso de Parobé/RS
}

The context of emancipations in the 1980s: The case of Parobé/RS

El contexto de las emancipaciones em la década de 1980: El caso de Parobé/RS

\section{Jaison Volnir da Silva Bueno*1, Roswithia Webber ${ }^{2}$,}

${ }^{1}$ Bolsista de Aperfeiçoamento Científico e Graduado em História pela Universidade Feevale, Novo Hamburgo, Rio Grande do Sul.

${ }^{2}$ Doutora em História, Professora titular do Curso de História da Universidade Feevale. Univesidade Feevale, Rio Grande do Sul.

*Correspondência: jaisonvolnir@yahoo.com.br

\section{RESUMO}

O presente estudo tem como objetivo apresentar o contexto em que ocorrem as emancipações municipais no Estado do Rio Grande do Sul, trazendo, como foco, o caso da cidade de Parobé. Buscaremos identificar o contexto do processos emancipatórios, bem como quais os aspectos principais para a efetivação dos mesmos. Quanto à metodologia utilizada na pesquisa, faz-se uso de pesquisa bibliográfica e documental, análise das diversas legislações a respeito das emancipações no Estado do Rio Grande do Sul, pesquisa em jornais de circulação local e estadual. Através da pesquisa, foi possível observar três pontos como fundamentais para a efetivação de uma emancipação municipal: cumprimento das exigências legais, apoio da população e atuação dos "atores políticos". As exigências legais dizem respeito ao cumprimento do que está determinado em lei. O apoio da população é efetivado através da realização de plebiscito e, por fim, a atuação dos atores políticos, que se refere as ações e estratégias realizadas para a efetivação da emancipação.

Palavras-chave: Emancipação; Atores Políticos; Plebiscito; Parobé; Rio Grande do Sul.

\section{ABSTRACT}

The present study aims to present the context in which municipal emancipations occur in the state of Rio Grande do Sul, focusing on the case of city Parobé. We will try to identify the context of the emancipatory processes, as well as what are the main aspects for their effectiveness. As for the methodology used in the research, we applied bibliographical and documental research, analysis of several legislations regarding emancipations in Rio Grande do Sul, research in newspapers of local and state circulation and documents that comprised the process of emancipation of Parobe city. Through the research it was possible to observe three points as fundamental for the realization of a municipal emancipation: compliance with legal requirements, support of the population and performance of "political actors". The legal requirements refer of to what is determined by the law. The support of the population is carried out through a plebiscite and, finally, the actions of political actors, refers to the actions and strategies carried out for the effectiveness of emancipation.

Keywords: Emancipation; Political Actors; Plebiscite; Parobé; Rio Grande do Sul

\section{RESUMEN}

El presente trabajo tiene como objetivo presentar el contexto en que ocurren las emancipaciones municipales em el Estado do Rio Grande do Sul, utilizando como foco el caso de la localidade de Parobé. Buscaremos identificar el contexto de los processos emancipatorios, así como los aspectos principales para la efectividad de los mismos. Encuanto a la metodología utilizada em la investigación, se hace uso de investigación bibliográfica y documental, 
análisis de las diversas legislaciones acerca de las emancipaciones en Rio Grande do Sul, búsqueda en periódicos de circulación local y estadual y documentos que componían el proceso de emancipación de Parobé. Por medio de la investigación fue posible observar três puntos como fundamentales para la realización de una emancipación municipal: ejecución de las exigências legales, apoyo de la población y actuación de los "actores políticos". Las exigências legales se refieren al cumplimiento de lo que se determina em la ley. El apoyo de la población se efectúa a través de la realización de plebiscito y, por fin, la actuación de los actores políticos se refiere a las acciones y estrategias realizadas para la implementación de la emancipación.

Descriptores: Emancipación; Actores Políticos; Plebiscito; Parobé; Rio Grande do Sul.

\section{INTRODUÇÃO}

Parobé é um município que está localizado na região metropolitana de Porto Alegre, Rio Grande do Sul, e se apresenta como um dos inúmeros municípios gaúchos que obtiveram a sua emancipação política na década de 80 , época em que as divisões territoriais do estado se acentuaram e formaram o grande número de unidades municipais que hoje compõem o Estado.

A emancipação de Parobé do município de Taquara ocorreu em 1982, e esse fato está inserido em um contexto político mais amplo. Com a perspectiva de apresentar como se dá o processo de emancipação política de uma localidade, como se dá o processo e quais as condições para tal, utiliza-se a localidade de Parobé como foco.

O presente artigo tem como objetivo apresentar o processo de emancipação, salientando aspectos relevantes para o processo e, também, as necessidades encontradas para as emancipações de localidades no Estado do Rio Grande do Sul, anteriores a 1980 e a partir dessa década.

Para tal, utilizou-se como metodologia a pesquisa bibliográfica e a documental. A pesquisa bibliográfica considerou estudos sobre o município de Parobé, bem como estudos teóricos no campo das Ciências políticas sobre o processo de emancipação. Nesse sentido, utilizou-se das ideias de Tomio (2005; 2003). A pesquisa documental contou com fontes primárias e secundárias. Dentre as fontes primárias foram consultadas as legislações locais, estaduais e nacionais vigentes sobre emancipação municipal. Como fontes secundárias foram utilizados jornais de circulação local e regional.

As emancipações municipais ocorrem principalmente, segundo Tomio (2003), por condições econômicas locais e interesses políticos, tratando-se de um processo jurídico que tramita dentro do legislativo estadual sob forma de projeto de lei, aprovado mediante o cumprimento das exigências constantes em lei.

$\mathrm{O}$ estudo permite compreender o processo emancipatório, traçar um paralelo entre a emancipação política de Parobé e os demais processos do Estado, identificando, assim, quais os principais aspectos que permeiam a obtenção da emancipação política por parte dos municípios.

O período, em questão, mostrava-se legalmente mais favorável para as divisões e desmembramentos territoriais no cenário brasileiro.

\section{PAROBÉ NO CONTEXTO DAS EMANCIPAÇÕES NO RS}

Tomio (2005), ao analisar o histórico de criações de municípios no Estado do Rio Grande do Sul, identifica que o primeiro aspecto que chama a atenção é a forma como que os processos são distribuídos no decorrer do tempo. Seu arranjo não se apresenta uniforme, sendo registrados períodos de grande explosão emancipacionista (principalmente a partir da década de 80) e outros sem nenhuma criação de novos municípios, ou mesmo extinções dessas 
unidades territoriais.

De acordo com Tomio (2005), esses períodos de maior ou menor número de municípios criados no Rio Grande do Sul estão diretamente ligados ao ambiente institucional e a legislação em vigor, que, em momentos, se apresentou mais permissiva em relação ao desmembramento de unidades territoriais. A emancipação de Parobé se dá justamente em um contexto de grande número de emancipações municipais.

Considerando o histórico das emancipações no estado do Rio Grande do Sul, é possível observar que uma série de legislações regulou tais desmembramentos territoriais. Até 1946, as alterações nas divisões das unidades territoriais eram de responsabilidade das câmaras municipais, reflexo, ainda, da constituição castilhista de 1892, quando a Assembleia Legislativa era afastada das decisões políticas. Então:

O processo decisório era estabelecido pela Lei Orgânica de cada município. Em síntese as câmeras aceitavam os pedidos de anexação, desmembramento ou criação municipal; promoviam os plebiscitos e enviavam o projeto de emancipação ao governador do Estado. Esse ator, com base nos pré-requisitos firmados pela Constituição Estadual, vetava ou promulgava o decreto de criação municipal. (TOMIO, 2005, p.133).

A partir de 1946, as decisões a respeito de divisões territoriais passaram a ser responsabilidade exclusiva do executivo estadual. Em 1948 foi criada a primeira lei que tratava da regulação dos processos emancipatórios no estado: a Lei Complementar $n^{\circ}$ 534, que estabeleceu requisitos para as emancipações, como, por exemplo, população mínima para a área emancipada.

Em 1953, ocorreu uma nova modificação na legislação. A lei 2.116/53 determinava os anos com milésimos finais três e oito para a realização dos processos de emancipação, além da criação da Comissão Revisora Territorial, responsável por analisar as condições econômicas das áreas emancipandas. Além disso, foi estabelecida uma exigência mínima de vinte mil habitantes como requisito para a área que desejava a emancipação.

Em 1960, outra lei de emancipação de municípios foi criada. Segundo Tomio (2005), a antiga legislação dificultava o andamento do processo emancipatório. Sendo assim, a Lei 4.054 retirou a obrigatoriedade dos anos finais três e oito para a realização dos processos e, também, extinguiu a Comissão Revisora de Divisão Territorial.

Entrando em vigor esta nova lei, foi formada em Parobé, no ano de 1964, uma comissão emancipacionista para buscar o desmembramento político do distrito junto ao município de Taquara. Contudo, essa comissão não obteve sucesso. De acordo com Lígia Mosmann (1999), o insucesso desse movimento se deu pelo não preenchimento de todos os requisitos legais, sendo que a formação de um novo movimento emancipatório em Parobé ocorreu apenas dezoito ano mais tarde, em 1981. A situação político institucional em que se encontrava o Brasil naquele período interferiu no processo emancipacionista de Parobé.

A partir de 1964, o país começou a ser controlado pelo regime militar e a ditadura, com sua forte política centralizadora, evitou as divisões territoriais na federação. A explicação para o fim das emancipações estava na atuação dos militares:

Foi a ruptura institucional, a violência centralizadora, e as sanções políticas impostas pelo regime de 1964 que, claramente reconhecidas enquanto ameaças reais pelos atores políticos estaduais, cessou o surto emancipacionista dos anos 1950 e 1960. A regulamentação expressa na Lei Complementar federal $\mathrm{n}^{\circ} .01 / 1967$, acrescida a diminuição das transferências fiscais aos municípios, somente arrefeceu os ânimos (já violentamente apagados) do emancipacionistas gaúchos. (TOMIO, 2005, p. 135)

Dessa forma, as condições para as emancipações não eram favoráveis no período em 
que os militares estavam no poder, devido às sanções impostas pelo sistema. Logo, Parobé, que até então não havia conseguido a sua emancipação política, sofreu as consequências do contexto nacional, em que não havia nenhuma movimentação no sentido de se buscar desmembramentos de unidades territoriais nos municípios.

No início dos anos 1980, foram retomadas as discussões a respeito das emancipações. Segundo Tomio (2003), os interesses referentes às emancipações voltaram à pauta da Assembleia Legislativa do Estado. Além disso, havia um ambiente político mais favorável, o que possibilitou aos legisladores estaduais passarem novamente a controlar os processos e as decisões acerca das divisões de territórios municipais. Sendo assim, nesse contexto de abertura política, após uma forte centralização do poder praticada pelos militares, foi formado, em 1981, um novo movimento emancipatório em Parobé.

Pode-se constatar que a emancipação de Parobé estava numa conjuntura política completamente diferente dos demais processos que envolveram o município de Taquara. Os outros distritos alcançaram a sua autonomia com diferentes determinações legais, como Canela (1945), Gramado (1954), Três Coroas (1959) e Igrejinha (1964), que estavam em um cenário político diferenciado.

A emancipação de Igrejinha respondeu aos requisitos exigidos pela Lei 4.054/60, a mesma que Parobé, em 1982. No entanto, o contexto no qual ocorreu o processo de separação de Parobé do município de Taquara foi de reabertura política e institucional para as emancipações no Rio Grande do Sul. Esse panorama possibilitou que o distrito conseguisse o seu desmembramento praticamente duas décadas mais tarde que as demais localidades originárias de Taquara e que se tornasse o último distrito a conseguir a sua emancipação.

\section{ASPECTOS LEGAIS NO PROCESSO EMANCIPATÓRIO}

As emancipações municipais integram um processo que está condicionado a uma série de determinações que, ao serem cumpridas, dão possibilidade à unidade, que deseja desmembrar-se, de conseguir efetivar o seu desligamento. Assim, identifica-se a trajetória para a emancipação de Parobé, no ano de 1982, a partir do cumprimento de determinações legais.

Como citado anteriormente, Parobé obedeceu ao que estava disposto na Lei4.054/60, de 1960. Essa normativa regia os pontos que deveriam ser observados, pelos municípios que desejavam a sua emancipação política no Rio Grande do Sul, entre os anos de 1960 e 1988. A legislação tinha como principais requisitos mínimos para a criação de um município, os seguintes termos:

Art. $3^{\circ}$ - São condições essenciais para a criação de municípios:

I- População mínima de 12000habitantes. II-Receita suficiente para manutenção de seus serviços.

III-Possibilidade de desenvolvimento.

IV-Prévia anuência da maioria da população da área a ser emancipada da, mediante plebiscito. $\S 1^{\circ}$-Não será permitida a criação de municípios e, com os desmembramentos necessários a sua constituição alguns dos municípios já existente deixar de preencher qualquer das condições enumeradas nos três incisos desse artigo.

$\S 2^{\circ}$ - Não serão incorporados ao novo município as áreas que se manifestarem contra a sua criação desde que as indicadas exclusões não prejudiquem as exigências constantes aos incisos I, II e III desse artigo. (LEI 4.054/60, 1960).

A observação dessas exigências, permite a visualização daquilo que os municípios viriam ter que apresentar no seu processo de emancipação. A adequação da área emancipada à legislação vigente faz necessária, também, a configuração de outros aspectos, considerados importantes no processo de emancipação. 
O cumprimento dessas determinações possibilita um envolvimento de toda a comunidade que pleiteia a sua emancipação, não se restringe a um movimento de um grupo de pessoas representantes da classe política local. Uma vez que a lei prevê um plebiscito, a população é importante dentro da constituição do cenário jurídico que deve se formar para o prosseguimento do processo, cumprindo um papel político dentro do movimento, como ressalta Tomio (2005).

Parobé, na década de 1980, contava com as condições para buscar a emancipação. Sua grande arrecadação tributária, oriunda da forte indústria calçadista atuante desde a década de 1940, dava o amparo para comprovação das possibilidades de desenvolvimento local. Com a anexação de outras áreas territoriais ao processo de emancipação, a comissão responsável pelo andamento do processo conseguia atender às necessidades mínimas de população, e, por fim, a aprovação do processo pelos eleitores da localidade completava as exigências para o encaminhamento do pedido.

Para ao cumprimento das determinações legais no processo emancipatório, foi formado um grupo de pessoas que ficou responsável pela organização e levantamento de materiais, constituindo assim, uma comissão de emancipação. Dentro do que está disposto na Lei 4.054/60, às comissões compete preparar e formular os pedidos de emancipação, praticar todos os atos consequentes e representar os interesses da área emancipada.

Em Parobé, os líderes da comissão eram basicamente comerciantes da localidade, mas, junto a eles, havia alguns membros da política local e empresários, que mesclavam o perfil de membros que compuseram o grupo de emancipadores.

O grupo que compunha a comissão ficou responsável pela reunião de toda a documentação exigida no processo. Ao analisar o projeto de lei que criava o município de Parobé, é possível observar a série de exigências dentro de um pedido de emancipação. Com o acesso a esse projeto, observase que a documentação constante buscava comprovar as informações prestadas previamente antes da abertura do processo. Nota-se a presença de mapas da área, levantamentos topográficos, pedidos de consulta do número de moradores da localidade, junto ao IBGE (Instituto de Geografia e Estatística), relação de imóveis, entre outros documentos.

Dentre esses registros, é observada, também, a atuação da comissão de emancipação, na medida em que os documentos apresentam as suas respectivas assinaturas e tem os seus nomes listados como destinatários.

Em termos de composição da população, para que a emancipação pudesse ser pleiteada, a exigência legal era de 12.000 habitantes. Parobé, com levantamento do IBGE, chegou a 9.520 moradores na localidade. Para o cumprimento do mínimo exigido, Mosmann (1999) salienta que se buscou aumentar a área emancipada.

No PL 44/82, é constatado que houve um minucioso cumprimento de todas as demais determinações legais para o andamento do processo. Foram providenciadas declarações de arrecadação das empresas da localidade, para comprovar as possibilidades de desenvolvimento, constantes em lei, relação de recolhimento de ICMS das respectivas empresas, mapas especificando as áreas as quais a emancipação abrangeria e resultado do plebiscito emancipatório.

Com os membros da comissão à frente, dando o cumprimento das exigências legais, se fazia necessário para o projeto emancipacionista ser apreciado pela Assembleia Legislativa doestado.

As exigências legais, que deveriam ser observadas para o processo emancipatório de Parobé, também deveriam ser observadas nos demais 
processos no município do Rio Grande do Sul que estavam enquadrados na Lei 4.054/60. Ao tratar do processo de outros municípios, cabe observar que as referidas exigências podem diferir, à medida que a legislação à qual está submetido o processo de emancipação pode ser diferente. Sendo assim, considera-se o cumprimento dos requisitos legais como uma das principais partes do processo emancipatório.

\section{PLEBISCITO: O APOIO DA POPULAÇÃO MANIFESTADO NO VOTO}

Outro aspecto que se elenca como importante no processo emancipatório é a participação popular na efetivação e na legitimação do projeto emancipacionista. A população da localidade manifestava o seu apoio ou sua contrariedade durante todo o período em que as discussões a respeito da autonomia do distrito estavam em voga, mas é no plebiscito emancipatório, expressando a sua opinião por meio do voto, que o cidadão iria efetivamente se posicionar a respeito do tema que está sendo proposto.

Com a aprovação do processo de emancipação na Assembleia Legislativa, foi solicitada a realização do plebiscito junto à população, para, posteriormente, como resultado, ser encaminhado para a sanção do executivo estadual.

Feita a formalização do pleito, a consulta popular ficou marcada para o dia 28 de março de 1982, dando, assim, início às mobilizações dos grupos favoráveis e contrários à emancipação do município.

Pode-se observar que o plebiscito foi o momento de maior participação e mobilização da comunidade em torno do processo de emancipação. $\mathrm{O}$ embate das discussões acerca do desmembramento da localidade estava presente no dia a dia dos cidadãos.
O Jornal NH, veículo de circulação da região do Vale do Rio dos Sinos, assim caracterizou o distrito de Parobé, no cenário da campanha do plebiscito:

Nas semanas que antecederam o plebiscito, o único assunto discutido era a importância da emancipação política para a comunidade. Nas ruas da cidade, casas comerciais e nos prédios, diversas faixas com os dizeres "Vote sim no dia 28" eram encontradas. (JORNAL NH, 30. Mar 1982, p.2)

No Jornal Folha da Tarde, periódico de circulação estadual, a emancipação política foi o assunto que tomou conta do cotidiano dos moradores do distrito de Parobé. A edição do dia 25 de março de 1982 trouxe que "os bares ao redor da praça central, onde fica a sede da subprefeitura, ou mesmo na sala de recepção de alguma empresa, a conversa acaba sempre caindo no tema da emancipação" (FOLHA DA TARDE, 25 mar. 1982, p.12).

Os dois trechos dos periódicos, acima apresentados, conotam a forma com que o debate de ideias entre os moradores do distrito passou a ocorrer. Diferentemente das etapas do processo de emancipação, que até então tinham sido percorridas, o plebiscito passou a apresentar uma maior participação popular, enquanto as outras etapas abrangiam áreas jurídicas e burocráticas.

A campanha plebiscitária de Parobé caracterizou-se pela manifestação da maioria do eleitorado de forma favorável à divisão territorial. Essa preferência do eleitorado parobeense se alinha à ideia de Tomio (2002), em que os interesses das lideranças locais e do eleitorado da área a ser emancipada tendem a ser favoráveis à emancipação política. Como se verá posteriormente, a atuação de lideranças políticas, em especial deputados estaduais que mantém os seus "nichos" eleitorais dentro dos municípios, foram determinantes para a aceitação do eleitorado pela emancipação.

Em Parobé, é possível constatar o debate de ideias favoráveis e contrárias à emancipação. 
Encabeçando a parcela da comunidade que consentia com a separação, identifica-se os membros da comissão de emancipação como principais articuladores, juntamente com as demais lideranças e autoridades locais, da campanha pelo "sim".

Os principais argumentos levantados pelos favoráveis à emancipação eram as possibilidades de crescimento que o novo município teria a partir da separação de Taquara. Soluções para os problemas, principalmente de infraestrutura, eram apresentados para a população com a obtenção da emancipação do distrito. $\mathrm{O}$ grande número de empresas e a possibilidade de direcionamento dos investimentos desses recursos eram os principais argumentos, como salienta Henh (2017).

Apesar da grande aceitação da emancipação dentro da comunidade, havia grupos de moradores, principalmente de zonas mais periféricas do distrito, que se posicionavam contrariamente à emancipação de Parobé. A localidade de Santa Cristina do Pinhal apresentava movimento contrário ao processo.

Segundo Mosmann (1999), a oposição dos moradores de Santa Cristina do Pinhal estava fundamentada em duas causas, que eram a sua ligação histórica com o município de Taquara e sua posição geográfica. Quanto ao primeiro aspecto, Santa Cristina do Pinhal, que desde 1760 foi povoada por luso-brasileiros, era o município que deu origem à Colônia do Mundo Novo, que veio a se tornar, mais tarde, o município de Taquara.

Quanto a sua geografia, Santa Cristina do Pinhal, em relação ao distrito de Parobé, ficava na margem oposta do Rio dos Sinos, porém não havia ponte que fizesse a ligação entre as duas localidades. Logo, seria necessário aos moradores ir até Taquara para conseguir o acesso a Parobé. Além disso, havia a ideia de que, em caso de separação de Taquara, a vila perderia aquilo que possuía em relação à infraestrutura.
Para fazer contraponto às alegações dos contrários à emancipação, os emancipacionista realizavam a sua campanha na localidade trazendo propostas para essas dificuldades destacadas. Segundo Henh (2017), já havia articulações por parte dos emancipacionistas no governo estadual para a construção de uma ponte para fazer a ligação entre as duas localidades, e isso era salientado para a comunidade na campanha.

Pode-se observar, assim, que, no processo de emancipação municipal, muito mais que um momento de conclusão das prerrogativas legais exigidas pela legislação, é um momento de debate dentro da área que busca a separação.

Permeando essas discussões, há o interesse das lideranças políticas locais, que encabeçam os diálogos a respeito do processo e passam a servir de influência para o eleitorado local. Apesar das divergências na comunidade, o plebiscito ocorreu sem nenhum transtorno. A votação aconteceu nas sessões eleitorais do distrito e também nas áreas adjacentes, como Santa Cristina do Pinhal e Campo Vicente. Como esperado pelos emancipacionistas, o resultado do plebiscito foi a favor do movimento. Sendo assim, foi aprovada a emancipação do distrito de Parobé.

Analisando o ofício da apuração dos votos do plebiscito, podemos perceber que houve uma boa margem de votos favoráveis à emancipação. Mais especificamente, em um total de 3.976 votos, 2.463 votaram "sim" e 273 optaram pelo "não". Além desses, 35 votaram em branco, 7 nulos e 1.119 não compareceram aos locais de votação. (APURAÇÃO PLEBISCITÁRIA, 14 abr, 1982)

Com a oficialização do resultado da votação, pode-se observar que, por parte daqueles eleitores que compareceram às urnas de votação, houve uma grande aceitação da emancipação. Também é possível constatar que o número de eleitores que se abstiveram 
de seus votos foi elevada. Com a manifestação de sua preferência em emancipar o distrito de Parobé, por meio do voto, a comunidade se reuniu na praça central para comemorar o resultado do plebiscito. Nessas comemorações, foi possível constatar a presença de figuras que participavam do jogo político da emancipação.

As comemorações pela emancipação se estenderam dentro da área central da localidade, onde houve festa e realização de um churrasco. O jornal Zero Hora fez a cobertura do evento:

A apuração iniciada as 8 horas, findou às 10 horas quando até as escolas interromperam as suas aulas, para os alunos saírem às ruas para juntarem-se ao povo que cantava nas ruas a vitória do sim. Contudo, a grande comemoração promovida pela comissão emancipacionista só aconteceu após as 17 horas, com churrasco e passeata na Praça $1^{\circ}$ de maio, a principal do lugar e com desfiles de carros e grande presença de público. A carne, equivalente a três bois, foi toda doada. (ZERO HORA, 30 mar.1982, p.34)

Com o resultado do plebiscito conhecido e após a grande festa promovida pela comissão de emancipação para ser celebrado o resultado, o passo, para oficializar a criação do município de Parobé, foi a sanção do projeto por parte do governador do estado, José Augusto Amaral de Souza. Para tal, o resultado da consulta plebiscitária foi encaminhado pelo juiz eleitoral Geraldo César Fregapante à Assembleia Legislativa do estado, para que pudesse ser anexada a votação ao projeto e encaminhada ao governador.

A sansão que autoriza a criação do município de Parobé veio mais tarde, no dia 26 de abril de 1982. Com a Lei44/82, ficou estabelecida a criação de mais um município no estado do Rio Grande do Sul.

Diante da satisfação constatada por parte da população de Parobé, pode-se observar que o plebiscito não se limita a apenas mais uma etapa burocrática dentro dos aspectos legais dos processos de emancipação.
O momento de manifestação popular por meio do voto traz às urnas a posição da população da localidade que pleiteia a sua emancipação. Por intermédio da votação, foi possível delinear as regiões onde o projeto emancipacionista obteve maior ou menor apoio, podendo, ainda, ser levantadas não apenas questões políticas, mas também geográficas, como determinantes para a oposição à emancipação.

Partindo do caso analisado em Parobé, podese observar a importância do plebiscito no processo de emancipação, pois, por mais que a área que deseja desmembrar-se possua, do ponto de vista legal, todos os demais requisitos, apenas com o consentimento do voto de seus eleitores é possível dar prosseguimento ao processo. O plebiscito, portanto, é fundamental para assegurar de forma definitiva a participação popular e do jogo democrático dentro de um desmembramento territorial municipal.

\section{ATUAÇÃO DOS ATORES POLÍTICOS NO PROCESSO DE EMANCIPAÇÃO}

$\mathrm{O}$ último aspecto, que se considera como fundamental no processo emancipatório municipal, é a atuação dos atores políticos envolvidos na tramitação do projeto de emancipação política. Sua atuação é importante, pelo fato de serem, essas figuras, as principais envolvidas no andamento das etapas legais e pela comprovação dos requisitos constantes em lei para a aprovação da emancipação municipal.

Caracteriza-se os atores políticos como aquelas pessoas que estavam envolvidas na dinâmica do processo, considerando-se as relações políticas entre si, que podem ou não interferir em decisões a respeito de desmembramentos territoriais municipais. Tomio (2002) identifica quatro tipos de atores: lideranças políticas locais, eleitores, deputados estaduais e executivo estadual. 
As lideranças políticas locais são aqueles membros da comunidade que participam de forma mais ativa dentro do processo de emancipação. Além de políticos da comunidade, a atuação de comerciantes e demais figuras, que assumem condição de encabeçar o projeto emancipacionista, constituem essa parcela de atores políticos.

Tomio (2002) define as lideranças políticas locais como aqueles indivíduos que têm as suas residências estabelecidas na própria comunidade que aspirava emancipar-se e partiu deles a iniciativa de iniciar o processo emancipatório. Para isso, eles mobilizavam demais moradores em torno desse ideal, estabeleciam estratégias para compor o processo de emancipação, formavam comissões para montá-lo, buscavam o plebiscito e, também, exerciam pressão na representação política a nível estadual, ou seja, perante os deputados.

No caso de Parobé, é possível identificar que essas lideranças eram basicamente comerciantes da localidade. Junto a eles, havia alguns membros da política local, que mesclavam o perfil dos emancipadores. Foi possível identificar que, dentre os integrantes da comissão, treze pessoas eram comerciantes e empresários da localidade, enquanto três eram políticos.

A importância das lideranças políticas na montagem de estratégias para a viabilidade da emancipação municipal está no fato de que são essas pessoas, que por meio de suas relações, possibilitam o prosseguimento do processo.

Pode-se observar nas lideranças de Parobé, uma participação importante na construção do diálogo com políticos da Taquara, buscando soluções para os impasses surgidos pela criação do movimento. Também são essas lideranças que vão estabelecer relação de proximidade com figuras políticas dentro da Assembleia Legislativa, visando uma maior agilidade na tramitação do processo de emancipação no legislativo estadual.

Outra importante função desempenhada pelas lideranças políticas locais é a mobilização do eleitorado local para a realização do plebiscito emancipatório na localidade. Como se viu anteriormente, as lideranças tinham um papel importante na campanha pela aprovação do projeto emancipacionista, sendo eles responsáveis por apresentar as vantagens que os moradores da localidade passariam a ter em caso de concretização da emancipação, fazendo, também, contraponto as ideias contrarias que eram apresentada pelos opositores a emancipação da localidade.

Além das lideranças políticas, os eleitores desempenham um importante papel na emancipação municipal, cabendo a eles a decisão no plebiscito. Quanto aos eleitores, cabe ainda ressaltar, que são o foco de atuação das lideranças locais, favoráveis ou contrárias, que buscam votos para o processo emancipatório.

Uma terceira classe importante que atua como ator político no processo de emancipação são os deputados estaduais. Os deputados são os únicos que se fazem presentes em todas as instâncias na emancipação. Eles possuem vários instrumentos para controlar o processo, interagindo com os demais atores e, se necessário, interrompendo a sua tramitação dentro da casa legislativa.

Tomio (2002, p.48) define os interesses dos deputados dentro do processo:

Em cada manifestação do legislativo, maioria dos deputados não teria interesses significativos envolvidos. Para essa maioria não haveria um interesse fundamental na aprovação ou reprovação da emancipação do município. Em virtude disso, parto do pressuposto que o principal interesse da maioria dos deputados é a continuidade de sua carreira política. Individualmente, cada deputado definiria sua estratégia e escolheria o que maximiza sua chance de reeleição parlamentar ou de ocupação de outros cargos políticos. 
Como destaca o autor, é possível observar a aproximação de deputados e outras figuras do legislativo dentro do processo de Parobé. Pode-se ver o papel de dois deputados em específico: Aldo Pinto da Silva e Ivo Orlindo Mainardi, ambos do MDB. No projeto de lei 44/82, que tratava da emancipação do distrito de Parobé, identificamos uma atuação efetiva dos dois deputados em pedidos de análise de documentações e ambos, também, foram destinatários das solicitações da comissão de emancipação, mostrando uma aproximação entre a mesa e os parlamentares estaduais.

A presença desses deputados também foi notada na festa realizada no centro da localidade para comemorar a emancipação confirmada no plebiscito. Além dos deputados, a presença de outros atores políticos do processo foi percebida, como de eleitores, membros da comissão de emancipação e autoridades do município de Taquara (JORNAL NH, 01 abr.1982).

Um quarto ator político envolvido no processo é o executivo estadual. Tomio (2002) apresenta que o apoio do executivo estadual também estava alinhado com os interesses político que esse poder possui da área que compreendia a emancipação. Sua decisão, que poderia ser de apoio, oposição ou neutralidade, estava diretamente ligada ao seu alinhamento político. Caso os deputados fossem de oposição, o executivo poderia oferecer uma maior resistência ao andamento do projeto e vice-versa. $\mathrm{O}$ alinhamento político entre executivo e legislativo facilitava a tramitação do mesmo. Cabe lembrar que, acima do alinhamento político, também existe o interesse do executivo em manter o seu prestigio diante dos eleitores, tendo em vista uma futura manutenção da sua força política na região, onde ocorreu a emancipação.

Esses quatro atores políticos, que são apresentado por Tomio (2002), são determinantes para o andamento da emancipação, não somente no âmbito político, dentro de casas legislativas e executivas, como também dentro da sociedade em geral, que apresentava interesse na emancipação.

Em Parobé se observa a atuação dos quatro atores políticos em seu processo de emancipação: as lideranças políticas, manifestadas nas figuras dos membros da comissão de emancipação; os eleitores, que participaram do processo manifestando o seu voto no plebiscito; os deputados estaduais, apresentados nos deputados Aldo Pinto da Silva e Ivo Orlindo Mainardi, e, por fim, o executivo estadual, através do governador José Augusto Amaral de Souza.

É possível observar que o sucesso do processo emancipatório depende não só do cumprimento das exigências dispostas em lei, mas, também, da harmonia existente entre os atores políticos envolvidos. A comissão de emancipação depende do apoio de deputados estaduais, que facilitam a tramitação do processo na casa legislativa e da boa relação desses deputados como chefe do executivo, que é uma garantia uma futura sanção do processo.

Pode-se, assim, notar a importância dos atores políticos no processo de emancipação. Suas relações e decisões influem diretamente no andamento da emancipação e, também, na aceitação dos eleitores, consolidando assim o projeto de Parobé e os demais que buscavam a suas respectivas emancipações políticas.

\section{CONCLUSÃO}

Com o presente estudo, pode-se observar, a partir da emancipação política de Parobé, pontos que convergem com aspectos que são importantes para as emancipações municipais em geral. Primeiramente, observa-se que os aspectos legais e o ambiente 
institucional são fundamentais para início e andamento das divisões territoriais.

Em um segundo momento, foi possível constatar que o cumprimento das determinações legais foi fundamental para o caso de Parobé. Para se buscar a emancipação, a unidade territorial que almeja a sua separação precisa atender a uma série de pré-requisitos legais. Tais exigências servem para a comprovação que a localidade possui mínimas condições financeiras e de infraestrutura para se tornar um município independente.

Também foi possível observar, com o caso de Parobé, que a participação popular tem grande importância nas emancipações. A busca do apoio da população para o projeto emancipacionista, junto aos eleitores da localidade, além de ser uma exigência legal, serve, também, como forma de legitimar todo o movimento de emancipação junto à comunidade.

Por fim, a atuação dos atores políticos determina o andamento de todo o processo de emancipação, pois esse grupo de lideranças busca o cumprimento do que o consta em lei e mobilizar a população em torno da autonomia da localidade.

O processo de emancipação estudado no presente artigo salienta aspectos relevantes com relação às necessidades encontradas e atores envolvidos na emancipação de uma localidade no Estado do Rio Grande do Sul, no contexto dos anos de 1980. No entanto, a legislação analisada pautou a emancipação de outros municípios. Nesse sentido, considera-se importante a pesquisa destes processos em outros municípios, para a constituição da história local.

Com a realização do estudo, constatou-se uma certa dificuldade de levantamento de material a respeito de Parobé, grande parte em função da falta de cuidado dos acervos e, até mesmo, o descaso do poder público para com a memória do município.
O trabalho abre portas para futuros estudos a respeito dos processos históricos de Parobé, com foco tanto nos desdobramentos políticos com na emancipação ou em sua memória e identidade, de acordo com um viés da História Cultural.

\section{REFERÊNCIAS}

Diário Oficial do Estado. Arquivo Público do Estado do Rio Grande do Sul. Porto Alegre, 16.dez,1981.

FOLHA DA TARDE. 1982. Parobé: abstenção foi de $30 \%$ mas teve festa. Porto Alegre. 30, mar. p.12.

HENH, Aiser. Entrevista concedida a Jaison Volnir da Silva Bueno. Igrejinha: 09 set. 2017. Gravação em arquivo de mídia.

JORNAL NH. 1982. ATÉ a posse do prefeito, em janeiro, Parobé vai continuar ligado a Taquara. Novo Hamburgo, 01 abr. p.14.

1982. Desde domingo Parobé é o novo município gaúcho. Novo Hamburgo, 30 mar. p.2.

MOSMANN, Lígia. UMA FAZENDA, UM SOBRADO, A ESTAÇÃO...PAROBÉ, UMA HISTÓRIA A SER CONTADA. Parobé: Prefeitura Municipal de Parobé,1999.

Oficio de Apuração de Votação Plebiscitária. MUSEU HISTÓRICO DE PAROBÉ. Taquara, 01.Abr.1982.

Rio Grande Do Sul (estado). LEI 4.054, DE 29 DE DEZEMBRO DE 1960. Dispõe sobre a alteração da divisão territorial do estado. Disponível em:<http://www.al.rs.gov.br/legis/M010/M0100099. ASP

?Hid_Tipo $=$ TEXTO\&Hid_TodasNormas $=50573 \& \mathrm{hT}$ exto=\&Hid_IDNorma=50573> Acesso em: 19 ago. 2017.

LEI 2.116, DE 24 DE SETEMBRO

DE 1953. Dispõe sobre a alteração da divisão territorial do estado.Disponível em:<http://www.al.rs.gov.br/legis/M010/M0100018.a sp?Hid_IdNorma $=53329 \&$ Texto $=\&$ Origem $=1>$ Acesso em 19 ago.2017.

LEI 44, DE 26 DE ABRIL DE 1982. CRIA O MUNICÍPIO DE PAROBÉ. Disponível 
em:<http://www.acervomemorial.al.rs.gov.br/index.p hp/emancipacoes-dos-municipios-do-estado-do-riogrande-do-sul> Acesso 21 out.2017.

.LEI 7.574, DE 16 DE DEZEMBRO

DE 1981. Autoriza a realização de consulta plebiscitária no distrito de Parobé, pertencente ao município

de

Taquara.Disponívelem: $<$ http://www.al.rs.gov.br/legis/ M010/M0100018.asp?Hid_IdNorma=25038\&Texto= \&Origem=1>Acesso em 14 out. 2017.

TOMIO, Fabricio Ricardo de Limas. Federalismo, municípios e decisões legislativas: a criação de municípios no Rio Grande do Sul. REVISTA DE SOCIOLOGIA POLÍTICA, Curitiba ,jun.2005. Disponível em: $<$ http://www.scielo.br/scielo.php?pid=S0104$44782005000100009 \&$ script=sci_abstract $\&$ tln= pt>Acesso em: 24 set. 2017.

Decisões estaduais em períodos democráticos: a criação de municípios no RS antes de 1964 e após Constituição de 1988. In: XXVII ENCONTRO

ANUAL DA ANPOSCS, 2003, Caxambu-MG.

Disponível

em: $<$ httpp//:www.scielo.br/scielo.php?script+sci=s01

02-6909200010000> Acesso em:19 set.2017.
A criação de Municípios após a Constituição de 1988. REVISTA BRASILEIRA DE CIÊNCIAS SOCIAIS, V.17, $\mathrm{n}^{\circ} 48, \quad 2002$. Disponível em:<www.scielo.br/scielo.php?script+sci=S0110269092002000100006> Acesso em: 19 set. 2017.

ZERO HORA. 1982. Churrasco na comemoração da vitória. Porto Alegre 30, mar. p.34. 